\title{
Understanding the Physiological Links Between Physical Frailty and Cognitive Decline
}

\author{
Lina $\mathrm{Ma}^{1,2}$, Piu Chan ${ }^{1,2,3,4}$ \\ ${ }^{1}$ Department of Geriatrics, Xuanwu Hospital, Capital Medical University, Beijing Institute of Geriatrics, Beijing, \\ China \\ ${ }^{2}$ China National Clinical Research Center for Geriatric Medicine, Beijing, China \\ ${ }^{3}$ Department of Neurology and Neurobiology, Xuanwu Hospital, Capital Medical University, Beijing, China \\ ${ }^{4}$ Key Laboratory for Neurodegenerative Disease of the Ministry of Education, Beijing Key Laboratory for \\ Parkinson's Disease, Parkinson Disease Center of Beijing Institute for Brain Disorders, Beijing, China
}

[Received April 9, 2019; Revised May 20, 2019; Accepted May 21, 2019]

\begin{abstract}
Declines in both physical and cognitive function are associated with increasing age. Understanding the physiological link between physical frailty and cognitive decline may allow us to develop interventions that prevent and treat both conditions. Although there is significant epidemiological evidence linking physical frailty to cognitive decline, a complete understanding of the underpinning biological basis of the two disorders remains fragmented. This narrative review discusses insights into the potential roles of chronic inflammation, impaired hypothalamic-pituitary axis stress response, imbalanced energy metabolism, mitochondrial dysfunction, oxidative stress, and neuroendocrine dysfunction linking physical frailty with cognitive decline. We highlight the importance of easier identification of strategic approaches delaying the progression and onset of physical frailty and cognitive decline as well as preventing disability in the older population.
\end{abstract}

Key words: physical frailty, cognitive decline, biology, cognitive frailty

Declines in both physical and cognitive function are associated with increasing age. Frailty is characterized by failure of homeostatic mechanisms and vulnerability to adverse outcomes [1]. The prevalence of frailty is 3.5$51.4 \%$ across different geographical regions [2-6]. However, there is no consensus regarding the single definition of frailty for clinical application. There are two major operational definitions for frailty. The most widely used concept is the Fried physical frailty phenotype, which defines frailty based on three or more of the following five symptoms: unintentional weight loss, slowness, weakness, exhaustion, and low physical activity [7]. Sarcopenia, a condition of loss of muscle mass and function, increases the risk of physical frailty and is associated with cognitive impairment [8]. The second widely used concept is Rockwood frailty index composes many clinical conditions and diseases[9] and is a marker of deficits accumulation based on comprehensive geriatric assessment [10]. Both physical frailty and frailty index are associated with late-life cognitive impairment $[11,12]$.

Cognitive frailty was defined as the simultaneous presence of physical frailty operationalized based on the

*Correspondence should be addressed to: Dr. Lina Ma, Department of Geriatrics, Xuanwu Hospital, Capital Medical University, China National Clinical Research Center for Geriatric Medicine, Beijing 100053, China, E-mail: malina0883@126.com.

Copyright: () 2019 Ma L et al. This is an open-access article distributed under the terms of the Creative Commons Attribution License, which permits unrestricted use, distribution, and reproduction in any medium, provided the original author and source are credited. 
Fried phenotypic model and mild cognitive impairment (MCI) without dementia by an international consensus group from the International Academy of Nutrition and Aging (IANA) and the International Association of Gerontology and Geriatrics (IAGG) [13]. Recently, two subtypes of the new construct were proposed: reversible cognitive frailty and potentially reversible cognitive frailty [14]. An updated version of cognitive frailty model is presented in Figure 1. The prevalence of cognitive frailty ranges from $10.7 \%$ to $22.0 \%$ in clinical-based setting and from $1.0 \%$ to $4.4 \%$ in population-based setting [15]. Cognitive frailty is associated with increased risk of functional disability, poor quality of life, and mortality.

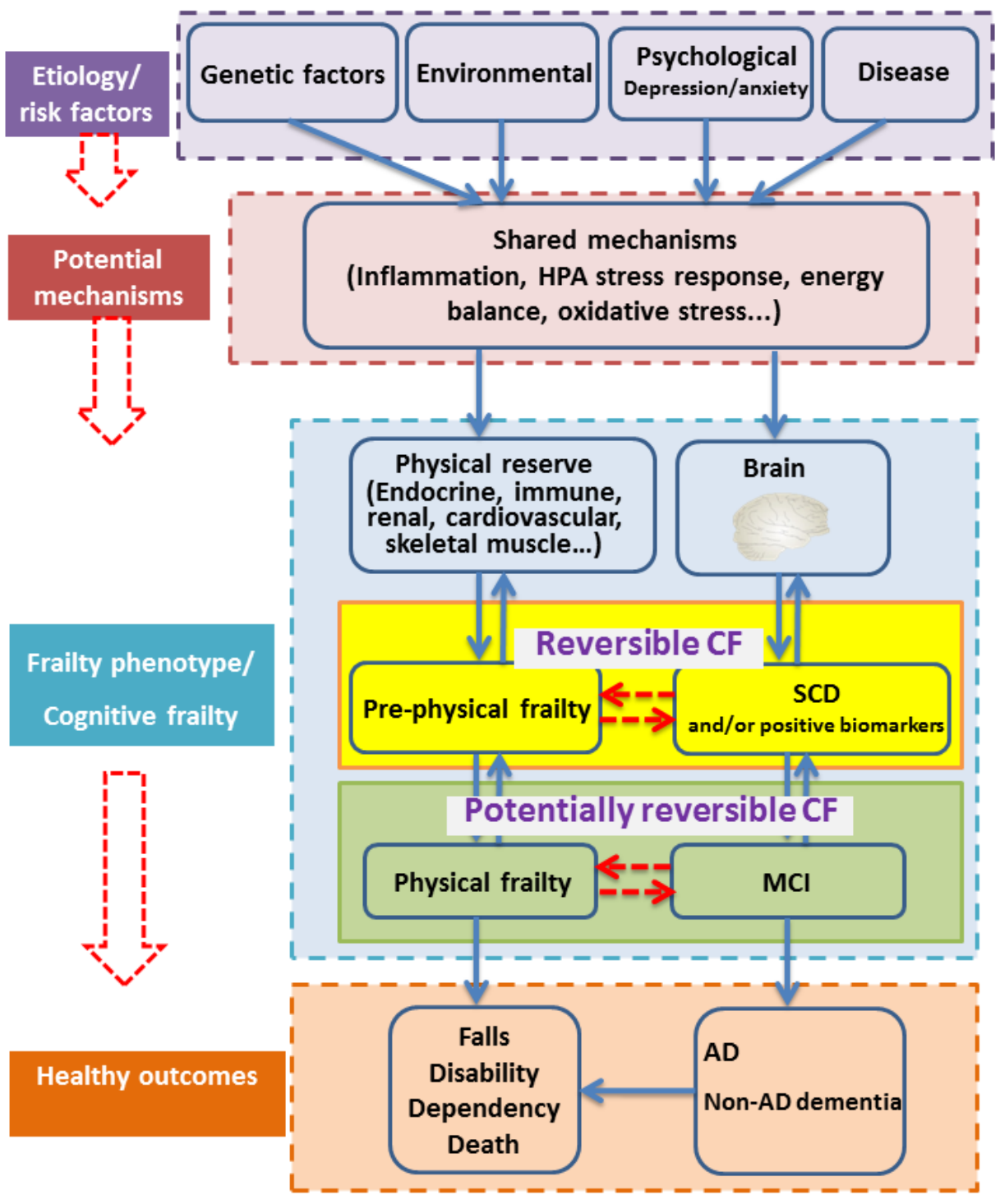

Figure 1. The model of cognitive frailty. Physical frailty and cognitive impairment have the same etiology, and might share the same mechanisms, which lead to adverse health outcomes. The decline in physical reserve and cognitive function contribute to frailty and cognitive impairment separately. Cognitive frailty is the combination of frailty and cognitive impairment in absence of dementia, which is further divided into reversible cognitive frailty (prefrailty and subjective cognitive decline) and potentially reversible cognitive frailty (physical frailty and mild cognitive impairment).Abbreviations: $\mathrm{CF}$, cognitive frailty; SCD, subjective cognitive decline; MCI, mild cognitive impairment; AD, Alzheimer's disease. 
Understanding the physiological link between physical frailty and cognitive decline may allow us to develop interventions that prevent and treat both conditions and thus, improve independent function and quality of life in older individuals. Although there is significant epidemiological evidence linking physical frailty to cognitive decline $[11,12,16]$, a complete understanding of the underpinning biological basis of the two conditions remains fragmented. The mechanisms underlying cognitive-frailty link are multifactorial since inflammatory, nutritional, vascular, and metabolic factors may be involved [17]. Sarcopenia may also explain this link [15]. Aging is associated with immunosenescence, which is characterized by declines in adaptive and innate immunity [18]. The central nervous system and the immune system are constantly interacting [19]. In addition, impaired hypothalamic-pituitary axis (HPA) stress responses, imbalanced energy metabolism, mitochondrial dysfunction, oxidative stress, and neuroendocrine dysfunction may be associated with both physical and cognitive decline, and thus may be involved in mechanisms underlying the link between physical frailty and cognitive decline (Fig. 2).

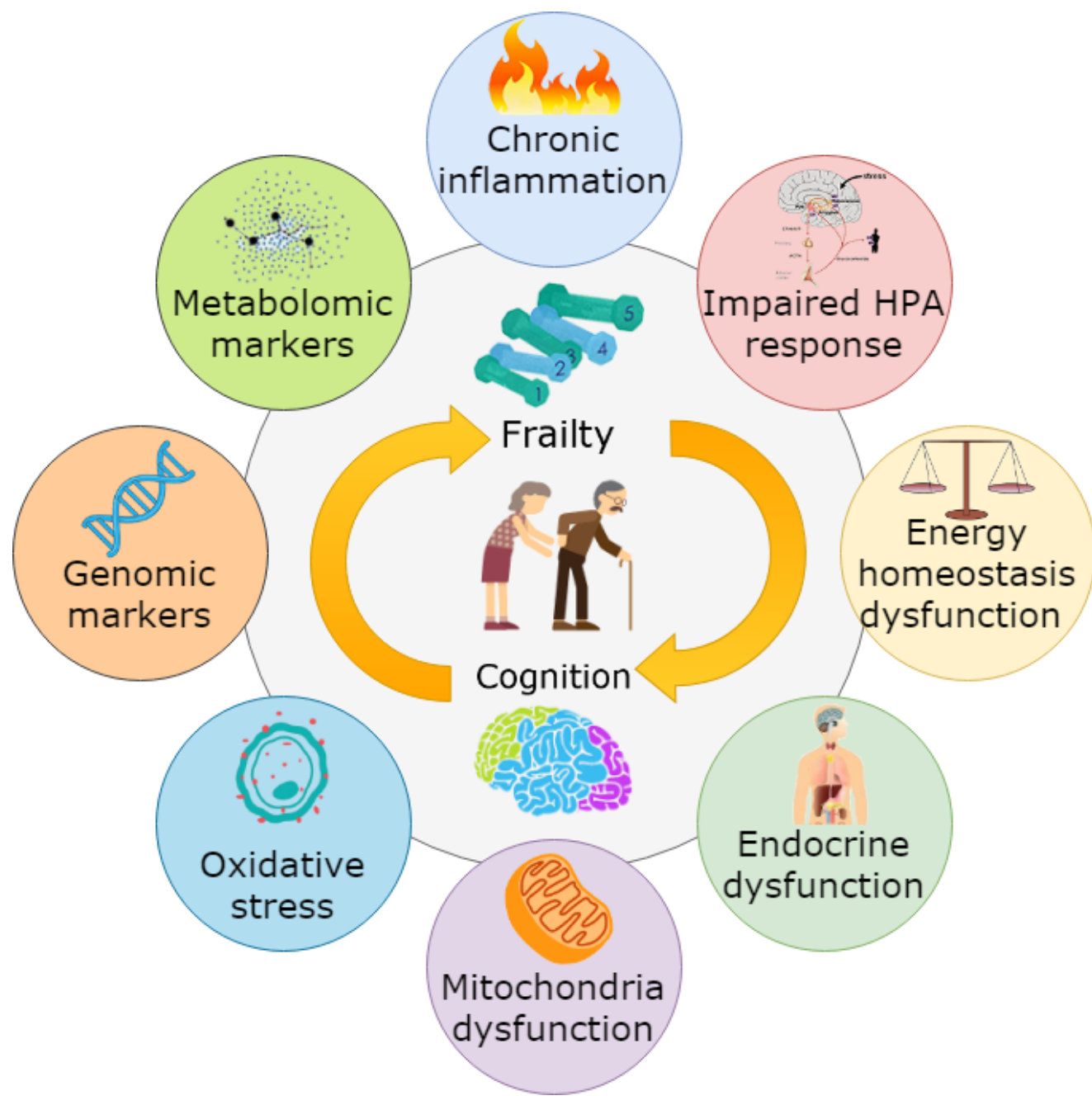

Figure 2. Overview of the underlying mechanisms linking physical frailty to cognitive decline. Chronic inflammation, impaired HPA stress response, imbalanced energy metabolism, endocrine dysregulation, mitochondrial dysfunction, oxidative stress, genomic markers and metabolomic markers are major underlying mechanisms between physical frailty (muscle) and cognitive decline (brain).

\section{Chronic inflammation}

Inflammaging refers to the low-grade systemic proinflammatory state resulting from the upregulation of the inflammatory response driven by multiple factors in old age $[20,21]$. It is characterized by high susceptibility to morbidity, frailty, disability, and mortality [22]. Chronic inflammation is associated with poor physical 
performance [23]. Pro-inflammatory cytokines include interleukin 6 (IL-6), IL-1 $\beta$, IL-12, and tissue necrosis factor alpha (TNF- $\alpha$ ) as well as C-reactive protein (CRP). Chronic inflammation contributes to the increased risk of frailty, potentially mediated via neurodegeneration [24]. TNF- $\alpha$ and IL- 6 influence the onset of frailty and cognitive decline [25], and CRP levels link muscle quality with cognitive function [26]. Anti-inflammatory cytokines include IL-10, IL-4, IL-13, and IL-1Ra [27]. The deregulated balance between the pro- and antiinflammatory status may induce lower physical function, thus affecting the central nervous system, and is involved in the pathophysiological mechanisms of frailty and dementia.

Frailty is associated with chronic inflammation [28]. High levels of IL-6, TNF- $\alpha$, and CRP were found to be associated with poor function and mobility status [29,30], lower muscle strength and muscle mass, and frailty in older individuals [31-35]. Systemic inflammation enhanced inflammatory responses within the central nervous system, contributing to cognitive decline [36,37]. Peripheral cytokines showed a direct influence on the central nervous system [19]. High levels of IL-1, IL-6, CRP, and TNF- $\alpha$ were also found to be potentially predictive markers for the development of Alzheimer's disease (AD) or cognitive decline [38-42]. Some studies showed that high levels of CRP were found in senile plaques and neurofibrillary tangles in the brain of $\mathrm{AD}$ patients $[43,44]$. However, other studies have failed to show the relationship between chronic inflammation and cognitive decline $[45,46]$.

IL-6 is the most important cytokine in inflammaging. Serum IL-6 levels increase with age, independent of other comorbid disease processes $[47,48]$, and are associated with poor physical performance (slower gait velocity and muscle weakness) and worse cognitive function. Rise in serum IL-6 levels are predictive of poor physical and cognitive performance, disability, and mortality in the older population $[30,34,49-55]$. IL-6 and the IL-6 receptor (IL-6R) promote chronic inflammation in the central nervous system and contribute to the development of AD [56]. Higher IL-6 levels are associated with muscle atrophy [57] and global and hippocampal atrophy [58], and may account for the association between $\mathrm{AD}$ pathology and frailty, independent of a dementia diagnosis [59]. TNF- $\alpha$ and its soluble receptor had the strongest association with muscle mass and strength decline in older persons [60]. Moreover, they were associated with both functional and cognitive decline [61]. Elevated TNF- $\alpha$ levels in the cerebrospinal fluid (CSF)[62], serum [63], and brain [64] have been observed in AD patients. High plasma TNF- $\alpha$ levels are predictive of muscle strength and cognitive declines $[60,65]$. Soluble TNF receptor 1 (sTNFR1) can differentiate between MCI and $\mathrm{AD}$ and may be helpful in determining the degree of cognitive impairment [66]. As an anti-inflammatory cytokine, lack of IL-10 leads to increased expression of nuclear factor- $\kappa \mathrm{B} \quad(\mathrm{NF}-\kappa \mathrm{B})$-induced inflammatory mediators [67], reduced skeletal muscle energy metabolism, and reduced release of free energy [68]. Moreover, IL-10 was negatively associated with executive function and processing speed. Higher neutrophil and monocyte counts, as well as lower lymphocyte counts, were associated with low physical activity [69] and frailty [70]. Elevated fibrinogen levels were associated with frailty[28], and decline in cognition [71,72], and predicted the onset of cognition deficits [46].

Recently, multivariable measures of inflammation provided an easier approach to track the progression of frailty over time. For instance, the inflammatory index score based on IL-6 and sTNFR1 has been shown to best describe age-associated chronic inflammation as well as predict mortality; moreover, the score was higher in frail older adults than in robust participants [73]. An index based on seven circulating inflammatory molecules was independently associated with deteriorating mobility function and frailty risk [74]. The above indexes were not studied in cognition.

\section{Hypothalamic-pituitary axis stress response dysfunction}

The HPA axis dysfunction is a pathway that contributes to both physical frailty and cognitive decline. The levels of dehydroepiandrosterone sulfate (DHEA-S), testosterone and growth hormone $(\mathrm{GH})$ decrease, while cortisol levels increase with age [75-77]. Multiple hormonal changes play a major role in the development of frailty, sarcopenia, cognitive decline and mortality in older adults $[77,78]$.

Cortisol, a lipophilic steroid hormone produced in the cortex of the adrenal glands, contributes to vulnerability to stressors in frail patients. Frail older adults display higher levels and blunted diurnal variation of cortisol $[76,79,80]$. Increased basal cortisol levels contribute to cognitive decline and may be associated with decreased hippocampal volume in $\mathrm{AD}$ patients [81]. Higher levels of cortisol were associated with lower brain volume and impaired memory in asymptomatic younger to middleaged adults [82] and worse performance in cognitive domains in adults aged 50 to 70 years [81].

Reduced testosterone levels may mediate the relationship between physical frailty and cognitive decline. Age-related depletion of testosterone was associated with muscle mass decline [83]. Grip strength and physical activity were associated with total testosterone levels [84]. Testosterone had protective effects on cognition by promoting synaptic plasticity in 
the hippocampus and regulating the accumulation of $A \beta$ protein [77]. Reduced androgen hormone levels may be related with both frailty and cognitive decline, and some hormonal changes have been shown to directly influence skeletal muscle decline and cognition [77,83]. DHEA-S was also lower in frail people [85].

GH levels decrease with age and are related to both frailty and cognitive impairment [86]. Learning and memory are induced by GH, and GH therapy could improve cognition, especially in behavioral disorders of the central nervous system [87]. GH-releasing hormone therapy has a positive effect on cognition in MCI participants [88].

\section{Energy homeostasis dysfunction}

Energy homeostasis dysfunction may provide another link between physical frailty and cognition. Decreased serum levels of the anabolic hormone insulin-like growth factor -1 (IGF-1), were found in both frail older adults [89,90] and $\mathrm{AD}$ patients [91]. Elevated serum IGF-1 levels are positively correlated with physical performance [92], thigh muscle area and density [93], knee extensor strength, and difficulty in mobility-related tasks [94], and negatively associated with muscle cell apoptosis [95] and poor health outcomes [96]. Both the secretion and biological actions of IGF-1 are modulated by proinflammatory cytokines. The negative effect of IL-6 on muscle function is exerted through IGF-1[97], while the effect of IGF-1 on muscle function depends on IL-6 levels [98]. A pro-inflammatory state had a significant detrimental effect on frailty; only under normal endocrine function, in cognitively impaired older adults [24]. Hence, the combined influence in frailty and cognitive decline requires greater in-depth exploration.

Silent mating-type information regulation 2 homolog 1 (SIRT1) is a key regulator of aging-related metabolic changes. Serum SIRT1 levels declined with age [99], and low SIRT1 levels were found in both patients with AD and MCI [100] and frail participants [101]. Other studies showed that increased SIRT1 activity was associated with both delayed aging [102] and cognitive decline [103]. There is a paradoxical association between low serum SIRT1 levels and robustness [104]. A recent study showed that higher serum SIRT1 levels in frail older adults were associated with slow walking speed [105]. SIRT1 singlenucleotide polymorphisms (SNPs) and serum SIRT1 levels in older men were possibly more closely associated with nutrition and body composition than with aging and age-related conditions [106]. Another study found no association between frailty and serum SIRT1 levels [104]. Ghrelin contributes significantly to the development of both physical frailty and cognitive impairment by stimulating gastric acid secretion, regulating glucose metabolism and energy homeostasis, and improving learning and memory [107]. Frail women had lower levels of fasting and $120 \mathrm{~min}$ ghrelin [108]. Ghrelin deletion prevented the decline in muscle strength and endurance by attenuating the decrease in phosphorylated adenosine monophosphate-activated protein kinase and increasing the number of type IIa muscle fibers [109]. Ghrelin was also involved in the neuro-modulation, neuro-protection and memory and learning processes [110]. Reduced ghrelin levels were associated with MCI in type 2 diabetes (T2DM) populations [111] and with metabolic changes in AD patients [112]. However, a recent study found that ghrelin modulated encoding-related brain function without enhancing memory formation in humans [113].

\section{Endocrine dysregulation}

Endocrine dysregulation is involved in the progression of physical frailty and cognitive decline by accelerating immunosenescence, attenuating neuroprotective and neurotrophic effects, and promoting muscle catabolism [114]. Clegg reviewed evidence on the association between frailty and the endocrine system [115]. However, the role of endocrine alterations in the etiology of frailty and cognitive decline is still poorly understood. Circulating adiponectin and leptin have been interrogated in many studies with conflicting results.

Insulin resistance (IR) was associated with incident frailty and poor cognitive function [116-119]. Higher Homoeostatic Model Assessment for IR index values were associated with a higher risk of frailty[120]. AD is considered as type 3 diabetes mellitus [121]; IR is an important risk factor for cognitive impairment in older adults [119,122]. Furthermore, rosiglitazone could improve learning and memory ability by normalizing the impaired insulin signaling pathway in diabetic rats [123]. Vaspin is a visceral adipose tissue-derived serine protease inhibitor with insulin-sensitizing effects associated with IR. Circulating vaspin levels increased with aging and were associated with parasympathetic activity even in the absence of metabolic syndrome [124]. Frail older adults showed higher levels of vaspin compared to participants who did not show frailty [125].

Adiponectin is a pleiotropic adipokine inversely correlated with adipose tissue dysfunction. Epidemiological findings indicate a paradoxical involvement of adiponectin in the health status. High levels of adiponectin were associated with decreased muscle strength [126], grip strength [125], frailty [125], increased number of frailty components [127], higher incidence of cardiovascular diseases and disability, and high mortality rate [128], but a low risk of T2DM [129]. Adiponectin levels have been associated with MCI and $\mathrm{AD}$, while higher plasma adiponectin was associated with 
poor cognitive performance, neuroimaging and cognitive outcomes in women [130]; in addition, another study showed that serum adiponectin was positively associated with better cognition in the postmenopausal period [131]. The adipocyte-derived hormone leptin regulates body weight and metabolism. Its secretion links food intake and energy reserves with energy expenditure, growth, and reproduction. Higher leptin levels were associated with higher risk of frailty, which was modestly explained by IR and chronic inflammation [132]. Circulating leptin was inversely correlated with gait speed [125]. Increasing leptin levels with increasing muscle mass showed positive effects on the skeleton mas s[133]. Leptin receptors impact cognitive function by affecting hippocampal synaptic plasticity [134]. Leptin resistance was linked with the development of AD [135]. High levels of leptin were associated with improved cognition in T2DM patients [136], while other studies found no association with function or global cognition [61], and blood leptin levels were not correlated with cognition in AD patients [137].

\section{Mitochondrial dysfunction}

Mitochondria contribute to the dynamics of cellular metabolism and reactive oxygen species (ROS) production. Thus, their role in aging has drawn much attention over the years. Increased levels of free radicals activate the NF- $\kappa$ B pathway. Mitochondrial function has been associated with physical function and vulnerability to disease in older adults [138-140]. The accumulation of mitochondrial and nuclear DNA damage leads to the loss of myocytes and muscle wasting [141]. Recent studies found that improving mitochondrial function reduced metabolic, visual, motor, and cognitive decline in aged Drosophila melanogaster [142].

Mitochondria are important sources of endogenous damage-associated molecular patterns and activate an innate immune response [143,144]. Mitochondrial DNA (mtDNA) is a known surrogate marker of whole-body mitochondrial function [145]. Low mtDNA levels were associated with frailty, poor physical strength and mortality, while high mtDNA levels were associated with better health and longevity $[138,139]$. Some studies have found that mtDNA levels in plasma increased with age [146]. Increased plasma mtDNA is a marker of ongoing inflammation and better neurocognitive function in virologically suppressed HIV-infected individuals [147]. However, further investigation is required to elucidate how mtDNA activates inflammation during the development and progression of physical frailty and cognitive decline.

Table 1. The potential biomarkers between physical frailty and cognitive decline.

\begin{tabular}{|c|c|}
\hline Physiological links & Potential biomarkers \\
\hline Chronic inflammation & IL-6, IL-1 $\beta$, IL-12, TNF- $\alpha$, CRP, IL-10, IL-4, IL-13, IL-1Ra, sTNFR1 \\
\hline Impaired HPA stress response & DHEA-S, GH, Cortisol, testosterone \\
\hline Imbalanced energy metabolism & IGF-1, SIRT1, Ghrelin \\
\hline Endocrine dysregulation & IR, vaspin, adiponectin, leptin \\
\hline Mitochondrial dysfunction & mtDNA \\
\hline Oxidative stress & ROS \\
\hline Metabolomic markers & 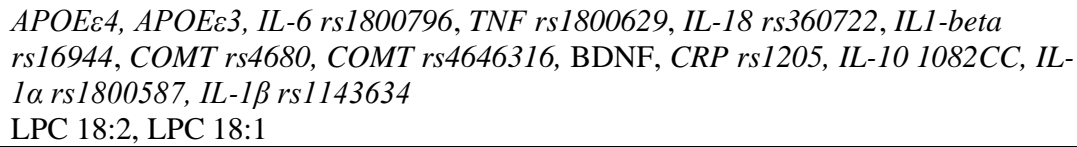 \\
\hline
\end{tabular}

Abbreviations: IL, interleukin; TNF- $\alpha$, tissue necrosis factor alpha; CRP, C-reactive protein; sTNFR1, Soluble TNF receptor 1; HPA, hypothalamic-pituitary axis; DHEA-S, dehydroepiandrosterone sulfate; GH, growth hormone; IGF-1, insulin-like growth factor -1; SIRT1, Silent mating-type information regulation 2 homolog 1; IR, Insulin resistance; ROS, reactive oxygen species; mtDNA, mitochondrial DNA; ApoE, Apolipoprotein E; BDNF, Brain-derived neurotrophic factor; LPC, lysophosphatidylcholine.

\section{Oxidative stress}

Frailty and cognitive decline are associated with oxidative stress (OS). OS was associated with accelerated aging, normal brain aging, and neurodegenerative diseases [148]. Oxidative damage accumulated with age and impaired cellular and organ function [149]. ROS contributed to skeletal muscle damage $[150,151]$. A recent review showed that frailty was associated with higher OS [152]. In the process of frailty, attenuated response of skeletal muscle to an increase in ROS levels contributed to a loss of ROS homeostasis and increased oxidative damage and age-related dysfunction in skeletal muscle [153]. Recently, Viña proposed a free-radical theory of frailty, postulating that oxidative damage is associated with frailty, but not with chronological age itself; their research on animals revealed that overexpression of antioxidant enzymes could delay the onset of frailty [154].

OS is associated with cognitive decline [155]. Chronic inflammation possibly alters immunological 
responses in the brain and further enhanced damage progression [156]. A pro-inflammatory environment with increased OS leads to endothelial dysfunction, which links cognitive impairment and frailty [148]. Thus, OS may serve as a common biological pathway that explains how physical frailty and cognitive decline are interrelated.

\section{Genomic markers}

Genetic background can interact with inflammation and other mechanisms involved in the process of physical frailty and cognitive decline. Apolipoprotein E (ApoE) was associated with lifespan and cognitive function [157]. Carriers of the APOE\&4 allele had reduced CRP levels $[158,159]$, and the association between increased CRP level and better cognition was observed only in older patients without the $A P O E \varepsilon 4$ allele $[160,161]$. When the aMCI group was stratified by the APOE 44 status, significant differences were found in the levels of IL-6 and IFN- $\gamma$ between the low- and high-risk groups and the control group [162], suggesting that some genetic factors are important. The loss of the $A P O E \varepsilon 4$ allele may be a vulnerability factor that contributes to the adverse effects of HPA axis dysregulation on cognition and has been suggested as the main risk factor for late-onset $\mathrm{AD}$, while the $A P O E \varepsilon 3$ allele was associated with a more adaptive HPA axis response [163].

Six genes were associated with frailty and cognitive decline in Sargent's recent review [164]: IL-6 rs 1800796 , TNF rs 1800629, IL-18 rs360722, IL1-beta rs 16944, and COMT rs 4680 for cognitive decline and COMT rs4646316 for frailty. Brain-derived neurotrophic factor (BDNF) is involved in neuronal survival/proliferation processes. Decreased BDNF levels were associated with cognitive impairment, AD [165] and frailty [166,167]. The inhibition or degradation of BDNF antisense RNA has been reported to upregulate $B D N F$ mRNA, increase BDNF protein levels, and induce neuronal growth and differentiation [168]. Thus, the SNP associated with BDNF may be related to the decreased plasma BDNF levels in frail people [166]. TNF rs 1800629 and CRP rs 1205 have been found to be associated with frailty [169,170]. IL-10 1082CC, associated with high serum levels of IL-10, was over-represented in centenarians [171]. $I L-1 \alpha \quad r s 1800587$ and $I L-1 \beta \quad r s 1143634$ were significantly associated with AD onset [172]. IL-6 gene variation was not associated with increased serum IL-6 levels or frailty $[173,174]$ and the $I L-6$ rs 1800795 gene was not associated with sporadic AD [175].

\section{Metabolomic markers}

Metabolomic markers may also contribute to the link between physical frailty and cognitive decline.
Dysregulation of lipid metabolisms, such as higher phosphatidylcholine (PC) and lysophosphatidylcholine (LPC) levels, play a prominent role in age-related diseases such as dementia [176,177]. Many important physiological and pathophysiological processes are regulated by lysophospholipids and LPC was involved in inflammation [178]. Low levels of LPC species, such as LPC 18:2 and LPC 18:1, were associated with inflammation [179], IR [179], and AD [176]. Recently, a longitudinal study found that lower levels of blood LPC 18:2 were an independent predictor of physical function decline in older adults [180].

\section{Conclusion}

Available evidence of the physiological links between physical frailty and cognitive decline from the observational studies is limited. The above findings provided initial insight into the potential roles of chronic inflammation, impaired HPA stress response, imbalanced energy metabolism, mitochondrial dysfunction, oxidative stress, and neuroendocrine dysfunction in the etiology of physical frailty and cognitive decline (Table 1). This provides important clinical implications for the easier identification of strategic approaches delaying the progression and onset of physical frailty and cognitive decline as well as preventing disability in the older population. Reversible functional and cognitive declines as defined in the construct of reversible cognitive frailty may be a target for secondary prevention for functional and cognitive impairment (Fig. 1), future clinical trials on biomarker-positive reversible cognitive frailty might be a promising direction $[15,181]$. While many biomarkers across multiple physiological systems are strongly associated with physical frailty and cognitive decline, it is notable that some results tend to be inconsistent between different studies, which poses a challenge and urgent need for future work on the physiological changes and identification of biomarkers for cognitive frailty.

\section{Competing and conflicts of interest}

None of the authors have any conflicts or competing interests in the article.

\section{Acknowledgments}

This work was supported by National Natural Science Foundation of China (81600927), National Key R\&D Program of China (2018YFC2002101, 2018YFC 1312001, 2017YFC0840105), Beijing Municipal Science \& Technology Commission (Z171100000117013), Beijing Municipal Administration of Hospitals' Mission Plan (SML20150803) and Milstein Medical Asian 
American Partnership Foundation Project Award in Geriatrics.

\section{References}

[1] Clegg A, Young J, Iliffe S, Rikkert MO, Rockwood K (2013). Frailty in elderly people. Lancet, 381(9868):752-762.

[2] Dent E, Dent E, Lien C, Lim WS, Wong WC, Wong CH, Ng TP, et al (2017). The Asia-Pacific Clinical Practice Guidelines for the Management of Frailty. J Am Med Dir Assoc, 18(7):564-575.

[3] Ma L, Tang Z, Zhang L, Sun F, Li Y, Chan P (2018). Prevalence of Frailty and Associated Factors in the Community-Dwelling Population of China. J Am Geriatr Soc, 66(3):559-564.

[4] Siriwardhana DD, Hardoon S, Rait G, Weerasinghe MC, Walters KR (2018). Prevalence of frailty and prefrailty among community-dwelling older adults in low-income and middle-income countries: a systematic review and meta-analysis. BMJ Open, 8(3): e018195.

[5] Gale CR, Cooper C, Sayer AA (2015). Prevalence of frailty and disability: findings from the English Longitudinal Study of Ageing. Age Ageing, 44(1): 1625.

[6] Ma L, Tang Z, Chan P, Walston JD (2019). Novel Frailty Screening Questionnaire (FSQ) Predicts 8-Year Mortality in Older Adults in China. J Frailty Aging, 8(1): 33-8.

[7] Fried LP, Tangen CM, Walston J, Newman AB, Hirsch C, Gottdiener J, et al (2001). Frailty in Older Adults: Evidence for a Phenotype. Journals Gerontol Ser A Biol Sci Med Sci, 56(3): M146-57.

[8] Szlejf C, Suemoto CK, Lotufo PA, Benseñor IM (2019). Association of sarcopenia with performance in multiple cognitive domains: results from the ELSABrasil study. Journals Gerontol Ser A. pii: glz118.

[9] Rockwood K, Andrew M, Mitnitski A (2007). A comparison of two approaches to measuring frailty in elderly people. J Gerontol A Biol Sci Med Sci, 62(7):738-43.

[10] Cesari M, Gambassi G, Abellan van Kan G, Vellas B (2014). The frailty phenotype and the frailty index: different instruments for different purposes. Age Ageing, 43(1):10-12.

[11] Wallace LMK, et al. (2019) Investigation of frailty as a moderator of the relationship between neuropathology and dementia in Alzheimer's disease: a cross-sectional analysis of data from the Rush Memory and Aging Project. Lancet Neurol, 18(2):177-184.

[12] Ma L, Zhang L, Sun F, Li Y, Tang Z (2019). Cognitive function in Prefrail and frail community-dwelling older adults in China. BMC Geriatr, 19(1):53.

[13] Kelaiditi E, Cesari M, Canevelli M, van Kan GA, Ousset PJ, Gillette-Guyonnet S, et al (2013). Cognitive frailty: Rational and definition from an (I.A.N.A./I.A.G.G.) International Consensus Group. J Nutr Heal Aging, 17(9):726-734.
[14] Ruan Q, Yu Z, Chen M, Bao Z, Li J, He W (2015). Cognitive frailty, a novel target for the prevention of elderly dependency. Ageing Res Rev, 20:1-10.

[15] Panza F, Lozupone M, Solfrizzi V, Sardone R, Dibello V, Di Lena L, et al (2018). Different Cognitive Frailty Models and Health- and Cognitive-related Outcomes in Older Age: From Epidemiology to Prevention. J Alzheimer's Dis, 62(3):993-1012.

[16] Ma L, Zhang L, Zhang Y, Li Y, Tang Z, Chan P (2017). Cognitive Frailty in China: Results from China Comprehensive Geriatric Assessment Study. Front Med, 4:174.

[17] Panza F, Solfrizzi V, Barulli MR, Santamato A, Seripa D, Pilotto A, et al (2015). Cognitive Frailty: A Systematic Review of Epidemiological and Neurobiological Evidence of an Age-Related Clinical Condition. Rejuvenation Res, 18(5):389-412.

[18] Fuentes E, Fuentes M, Alarcón M, Palomo I (2017). Immune System Dysfunction in the Elderly. An Acad Bras Cienc, 89(1):285-299.

[19] Rosano C, Marsland AL, Gianaros PJ (2012). Maintaining brain health by monitoring inflammatory processes: a mechanism to promote successful aging. Aging Dis, 3(1): 16-33.

[20] Franceschi C, Bonafè M, Valensin S, Olivieri F, De Luca M, Ottaviani E, et al (2000). Inflamm-aging. An evolutionary perspective on immunosenescence. Ann N Y Acad Sci, 908:244-54.

[21] Salvioli S, Capri M, Valensin S, Tieri P, Monti D, Ottaviani E, et al (2006). Inflamm-aging, cytokines and aging: state of the art, new hypotheses on the role of mitochondria and new perspectives from systems biology. Curr Pharm Des, 12(24): 3161-71.

[22] Ferrucci L, Fabbri E (2018). Inflammageing: chronic inflammation in ageing, cardiovascular disease, and frailty. Nat Rev Cardiol, 15(9):505-522.

[23] Langmann GA, Perera S, Ferchak MA, Nace DA, Resnick NM, Greenspan SL (2017). Inflammatory Markers and Frailty in Long-Term Care Residents. J Am Geriatr Soc, 65(8):1777-83.

[24] Tay L, Lim WS, Chan M, Ye RJ, Chong MS (2016). The Independent Role of Inflammation in Physical Frailty among Older Adults with Mild Cognitive Impairment and Mild-to-Moderate Alzheimer's Disease. J Nutr Heal Aging, 20(3):288-299.

[25] Michaud M, Balardy L, Moulis G, Gaudin C, Peyrot C, Vellas B, et al (2013). Proinflammatory cytokines, aging, and age-related diseases. J Am Med Dir Assoc, 14(12):877-882.

[26] Canon ME, Crimmins EM (2011). Sex differences in the association between muscle quality, inflammatory markers, and cognitive decline. J Nutr Health Aging, 15(8):695-698.

[27] Baylis D, Bartlett DB, Patel HP, Roberts HC (2013). Understanding how we age: insights into inflammaging. Longev Heal, 2(1):8.

[28] Soysal P, Stubbs B, Lucato P, Luchini C, Solmi M, Peluso R, et al (2016). Inflammation and frailty in the elderly: A systematic review and meta-analysis. Ageing Res Rev, 31:1-8. 
[29] Adriaensen W, Matheï C, van Pottelbergh G, Vaes B, Legrand D, Wallemacq P, et al (2014). Significance of serum immune markers in identification of global functional impairment in the oldest old: cross-sectional results from the BELFRAIL study. Age (Dordr), 36(1):457-67.

[30] Verghese J, Holtzer R, Oh-Park M, Derby CA, Lipton RB, Wang C (2011). Inflammatory Markers and Gait Speed Decline in Older Adults. Journals Gerontol Ser A Biol Sci Med Sci, 66A(10):1083-1089.

[31] Stenholm S, Maggio M, Lauretani F, Bandinelli S, Ceda GP, Di Iorio A, et al (2010). Anabolic and catabolic biomarkers as predictors of muscle strength decline: the InCHIANTI study. Rejuvenation Res, 13(1):3-11.

[32] Ferrucci L, Penninx BW, Volpato S, Harris TB, Bandeen-Roche K, Balfour J, et al (2002). Change in muscle strength explains accelerated decline of physical function in older women with high interleukin-6 serum levels. J Am Geriatr Soc, 50(12):1947-54.

[33] Pedersen BK, Bruunsgaard H (2003). Possible beneficial role of exercise in modulating low-grade inflammation in the elderly. Scand J Med Sci Sport, 13(1):56-62.

[34] Leng SX, Xue Q-LL, Tian J, Walston JD, Fried LP (2007). Inflammation and frailty in older women. J Am Geriatr Soc, 55(6):864-871.

[35] Walston J, McBurnie MA, Newman A, Tracy RP, Kop WJ, Hirsch CH, et al (2002). Frailty and activation of the inflammation and coagulation systems with and without clinical comorbidities: results from the Cardiovascular Health Study. Arch Intern Med, 162(20):2333-41.

[36] Yaffe K, Kanaya A, Lindquist K, Simonsick EM, Harris T, Shorr RI, et al (2004). The Metabolic Syndrome, Inflammation, and Risk of Cognitive Decline. JAMA, 292(18):2237-42.

[37] Dik MG, Jonker C, Hack CE, Smit JH, Comijs HC, Eikelenboom P (2005). Serum inflammatory proteins and cognitive decline in older persons. Neurology, 64(8):1371-1377.

[38] Su F, Bai F, Zhang Z (2016). Inflammatory Cytokines and Alzheimer's Disease: A Review from the Perspective of Genetic Polymorphisms. Neurosci Bull, 32(5):469-480.

[39] Shaik-Dasthagirisaheb Y, Conti P (2016). The Role of Mast Cells in Alzheimer's Disease. Adv Clin Exp Med, 25(4):781-787.

[40] Noble JM, Manly JJ, Schupf N, Tang MX, Mayeux R, Luchsinger JA (2010). Association of C-reactive protein with cognitive impairment. Arch Neurol, 67(1):87-92.

[41] Schram MT, Euser SM, de Craen AJ, Witteman JC, Frölich M, Hofman A, et al (2007). Systemic Markers of Inflammation and Cognitive Decline in Old Age. J Am Geriatr Soc, 55(5):708-716.

[42] Laurin D, David Curb J, Masaki KH, White LR, Launer LJ (2009). Midlife C-reactive protein and risk of cognitive decline: a 31-year follow-up. Neurobiol Aging, 30(11):1724-7.
[43] Duong T, Nikolaeva M, Acton PJ (1997). C-reactive protein-like immunoreactivity in the neurofibrillary tangles of Alzheimer's disease. Brain Res, 749(1):1526.

[44] Iwamoto N, Nishiyama E, Ohwada J, Arai H (1994). Demonstration of CRP immunoreactivity in brains of Alzheimer's disease: immunohistochemical study using formic acid pretreatment of tissue sections. Neurosci Lett, 177(1-2):23-6.

[45] Ravaglia G, Forti P, Maioli F, Chiappelli M, Montesi F, Tumini E, et al (2007). Blood inflammatory markers and risk of dementia: The Conselice Study of Brain Aging. Neurobiol Aging, 28(12):1810-1820.

[46] Rafnsson SB, Deary IJ, Smith FB, Whiteman MC, Rumley A, Lowe GD, et al (2007). Cognitive decline and markers of inflammation and hemostasis: the Edinburgh Artery Study. J Am Geriatr Soc, 55(5):7007.

[47] Wei J, Xu H, Davies JL, Hemmings GP (1992). Increase of plasma IL-6 concentration with age in healthy subjects. Life Sci, 51(25):1953-6.

[48] Wilson CJ, Finch CE, Cohen HJ (2002). Cytokines and cognition--the case for a head-to-toe inflammatory paradigm. J Am Geriatr Soc, 50(12):2041-56.

[49] Wu YY, Hsu JL, Wang HC, Wu SJ, Hong CJ, Cheng IH (2015). Alterations of the Neuroinflammatory Markers IL-6 and TRAIL in Alzheimer's Disease. Dement Geriatr Cogn Dis Extra, 5(3):424-34.

[50] Cesari M, Penninx BW, Pahor M, Lauretani F, Corsi AM, Rhys Williams G, et al (2004). Inflammatory markers and physical performance in older persons: the InCHIANTI study. J Gerontol A Biol Sci Med Sci, 59(3):242-8.

[51] Puzianowska-Kuźnicka M, Owczarz M, Wieczorowska-Tobis K, Nadrowski P, Chudek J, Slusarczyk P, et al (2016). Interleukin-6 and C-reactive protein, successful aging, and mortality: the PolSenior study. Immun Ageing, 13(1):21.

[52] Wright CB, Sacco RL, Rundek T, Delman J, Rabbani L, Elkind M (2006). Interleukin-6 Is Associated With Cognitive Function: The Northern Manhattan Study. J Stroke Cerebrovasc Dis, 15(1):34-38.

[53] Wassel CL, Barrett-Connor E, Laughlin GA (2010). Association of circulating C-reactive protein and interleukin-6 with longevity into the 80 s and 90s: The Rancho Bernardo Study. J Clin Endocrinol Metab, 95(10):4748-55.

[54] Varadhan R, Yao W, Matteini A, Beamer BA, Xue QL, Yang H, et al (2014) Simple biologically informed infammatory index of two serum cytokines predicts 10 year all-cause mortality in older adults. Journals Gerontol - Ser A Biol Sci Med Sci, 69 A(2):165-173.

[55] Yaffe K, Lindquist K, Penninx BW, Simonsick EM, Pahor M, Kritchevsky S, et al (2003). Inflammatory markers and cognition in well-functioning AfricanAmerican and white elders. Neurology, 61(1):76-80.

[56] Ershler WB, Keller ET (2000). Age-associated increased interleukin-6 gene expression, late-life diseases, and frailty. Annu Rev Med, 51(1):245-70. 
[57] Baltgalvis KA, Berger FG, Pena MM, Davis JM, Muga SJ, Carson JA (2007). Interleukin-6 and cachexia in ApcMin/+ mice. AJP Regul Integr Comp Physiol, 294(2):R393-R401.

[58] Satizabal CL, Zhu YC, Mazoyer B, Dufouil C, Tzourio C (2012). Circulating IL-6 and CRP are associated with MRI findings in the elderly: the 3C-Dijon Study. Neurology, 78(10):720-7.

[59] Buchman AS, Schneider JA, Leurgans S, Bennett DA (2008). Physical frailty in older persons is associated with Alzheimer disease pathology. Neurology, 71(7):499-504.

[60] Schaap LA, Pluijm SM, Deeg DJ, Harris TB, Kritchevsky SB, Newman AB, et al (2009). Higher inflammatory marker levels in older persons: Associations with 5-year change in muscle mass and muscle strength. Journals Gerontol - Ser A Biol Sci Med Sci, 64(11):1183-1189.

[61] Magalhães CA, Ferreira CN, Loures CMG, Fraga VG, Chaves AC, Oliveira ACR, et al (2018). Leptin, hsCRP, TNF- $\alpha$ and IL-6 levels from normal aging to dementia: Relationship with cognitive and functional status. J Clin Neurosci, 56:150-155.

[62] Tarkowski E, Blennow K, Wallin A, Tarkowski A (1999). Intracerebral production of tumor necrosis factor-alpha, a local neuroprotective agent, in Alzheimer disease and vascular dementia. J Clin Immunol, 19(4):223-30.

[63] Perry RT, Collins JS, Wiener H, Acton R, Go RC (2001). The role of TNF and its receptors in Alzheimer's disease. Neurobiol Aging, 22(6):873-83.

[64] Lanzrein AS, Johnston CM, Perry VH, Jobst KA, King EM, Smith AD (1998). Longitudinal study of inflammatory factors in serum, cerebrospinal fluid, and brain tissue in Alzheimer disease: interleukin-1beta, interleukin-6, interleukin-1 receptor antagonist, tumor necrosis factor-alpha, the soluble tumor necrosis factor receptors I and II, and alpha1-antichymotrypsin. Alzheimer Dis Assoc Disord, 12(3):215-27.

[65] Holmes C, Cunningham C, Zotova E, Woolford J, Dean C, Kerr S, et al (2009). Systemic inflammation and disease progression in Alzheimer disease. Neurology, 73(10):768-774.

[66] Faria MC, Gonçalves GS, Rocha NP, Moraes EN, Bicalho MA, Gualberto Cintra MT, et al (2014). Increased plasma levels of BDNF and inflammatory markers in Alzheimer's disease. J Psychiatr Res, 53:166-72.

[67] Ko F, Yu Q, Xue QL, Yao W, Brayton C, Yang H, et al (2012). Inflammation and mortality in a frail mouse model. Age (Omaha), 34(3):705-715.

[68] Akki A, Yang H, Gupta A, Chacko VP, Yano T, Leppo MK, et al (2014). Skeletal muscle ATP kinetics are impaired in frail mice. Age (Omaha), 36(1):21-30.

[69] Fernández-Garrido J, Navarro-Martínez R, BuiguesGonzález C, Martínez-Martínez M, Ruiz-Ros V, Cauli $\mathrm{O}$ (2014). The value of neutrophil and lymphocyte count in frail older women. Exp Gerontol, 54:35-41.

[70] Leng SX, Xue QL, Tian J, Huang Y, Yeh SH, Fried LP (2009). Associations of neutrophil and monocyte counts with frailty in community-dwelling disabled older women: Results from the Women's Health and Aging Studies I. Exp Gerontol, 44(8):511-516.

[71] Cortes-Canteli M, Zamolodchikov D, Ahn HJ, Strickland S, Norris EH (2012). Fibrinogen and altered hemostasis in Alzheimer's disease. J Alzheimers Dis, 32(3):599-608.

[72] Cortes-Canteli M, Paul J, Norris EH, Bronstein R, Ahn HJ, Zamolodchikov D, et al (2010). Fibrinogen and beta-amyloid association alters thrombosis and fibrinolysis: a possible contributing factor to Alzheimer's disease. Neuron, 66(5):695-709.

[73] Van Epps P, Oswald D, Higgins PA, Hornick TR, Aung $\mathrm{H}$, Banks RE, et al (2016). Frailty has a stronger association with inflammation than age in older veterans. Immun Ageing, 13(1):27.

[74] Bandeen-Roche K, Walston JD, Huang Y, Semba RD, Ferrucci L (2009). Measuring systemic inflammatory regulation in older adults: evidence and utility. Rejuvenation Res, 12(6):403-10.

[75] Travison TG, Nguyen AH, Naganathan V, Stanaway FF, Blyth FM, Cumming RG, et al (2011). Changes in reproductive hormone concentrations predict the prevalence and progression of the frailty syndrome in older men: the concord health and ageing in men project. J Clin Endocrinol Metab, 96(8):2464-74.

[76] Varadhan R, Walston J, Cappola AR, Carlson MC, Wand GS, Fried LP (2008). Higher levels and blunted diurnal variation of cortisol in frail older women. J Gerontol A Biol Sci Med Sci, 63(2):190-195.

[77] Maggio M, Dall'Aglio E, Lauretani F, Cattabiani C, Ceresini G, Caffarra P, et al (2012). The hormonal pathway to cognitive impairment in older men. J Nutr Health Aging 16(1):40-54.

[78] Morley JE, Malmstrom TK (2013). Frailty, sarcopenia, and hormones. Endocrinol Metab Clin North Am, 42(2):391-405.

[79] Holanda CM1, Guerra RO, Nóbrega PV, Costa HF, Piuvezam MR, Maciel ÁC (2012). Salivary cortisol and frailty syndrome in elderly residents of long-stay institutions: a cross-sectional study. Arch Gerontol Geriatr, 54(2):e146-51.

[80] Johar H, Emeny RT, Bidlingmaier M, Reincke M, Thorand B, Peters A, et al (2014). Blunted Diurnal Cortisol Pattern Is Associated With Frailty: A CrossSectional Study of 745 Participants Aged 65 to 90 Years. J Clin Endocrinol Metab, 99(3):E464-E468.

[81] Lee BK, Glass TA, McAtee MJ, Wand GS, BandeenRoche K, Bolla KI, et al (2007). Associations of Salivary Cortisol With Cognitive Function in the Baltimore Memory Study. Arch Gen Psychiatry, 64(7):810.

[82] Echouffo-Tcheugui JB, Conner SC, Himali JJ, Maillard P, DeCarli CS, Beiser AS, et al (2018). Circulating cortisol and cognitive and structural brain measures: The Framingham Heart Study. Neurology, 91(21):e1961-e1970.

[83] Muller M, Grobbee DE, Thijssen JHH, van den Beld AW, van der Schouw YT (2003). Sex hormones and 
male health: effects on components of the frailty syndrome. Trends Endocrinol Metab, 14(6):289-96.

[84] Mohr BA1, Bhasin S, Kupelian V, Araujo AB, O'Donnell AB, McKinlay JB (2007). Testosterone, sex hormone-binding globulin, and frailty in older men. $\mathrm{J}$ Am Geriatr Soc, 55(4):548-555.

[85] Leng SX, Cappola AR, Andersen RE, Blackman MR, Koenig K, Blair M, et al (2004). Serum levels of insulin-like growth factor-I (IGF-I) and dehydroepiandrosterone sulfate (DHEA-S), and their relationships with serum interleukin-6, in the geriatric syndrome of frailty. Aging Clin Exp Res, 16(2):153157.

[86] Nass R, Thorner MO (2002). Impact of the GH-cortisol ratio on the age-dependent changes in body composition. Growth Horm IGF Res, 12(3):147-61.

[87] Nyberg F, Hallberg M (2013). Growth hormone and cognitive function. Nat Rev Endocrinol, 9(6):357-365.

[88] Baker LD1, Barsness SM, Borson S, Merriam GR, Friedman SD, Craft S, et al (2012). Effects of Growth Hormone-Releasing Hormone on Cognitive Function in Adults With Mild Cognitive Impairment and Healthy Older Adults. Arch Neurol, 69(11):1420.

[89] Yeap BB1, Paul Chubb SA, Lopez D, Ho KK, Hankey GJ, Flicker L (2013). Associations of insulin-like growth factor-I and its binding proteins and testosterone with frailty in older men. Clin Endocrinol (Oxf), 78(5):752-9.

[90] Doi T, Makizako H, Tsutsumimoto K, Hotta R, Nakakubo S, Makino K, et al (2018) Association Between Insulin-Like Growth Factor-1 and Frailty Among Older Adults. J Nutr Health Aging, 22(1):6872.

[91] Watanabe T1, Miyazaki A, Katagiri T, Yamamoto H, Idei T, Iguchi T (2005). Relationship between serum insulin-like growth factor-1 levels and Alzheimer's disease and vascular dementia. J Am Geriatr Soc, 53(10):1748-53.

[92] van Nieuwpoort IC, Vlot MC, Schaap LA, Lips P, Drent ML (2018). The relationship between serum IGF1, handgrip strength, physical performance and falls in elderly men and women. Eur J Endocrinol, 179(2):7384.

[93] Colbert LH, Rosen CJ, Goodpaster BH, Newman AB, Kritchevsky SB, Satterfield S, et al (2004). Insulin-Like Growth Factor-1. J Am Geriatr Soc, 52(11):1962-1963.

[94] Cappola AR, Bandeen-Roche K, Wand GS, Volpato S, Fried LP (2001). Association of IGF-I Levels with Muscle Strength and Mobility in Older Women. J Clin Endocrinol Metab, 86(9):4139-4146.

[95] Perrini S, Laviola L, Carreira MC, Cignarelli A, Natalicchio A, Giorgino F (2010). The GH/IGF1 axis and signaling pathways in the muscle and bone: mechanisms underlying age-related skeletal muscle wasting and osteoporosis. J Endocrinol, 205(3):201-10.

[96] Kaplan RC, McGinn AP, Pollak MN, Kuller L, Strickler HD, Rohan TE, et al (2008). Total insulinlike growth factor 1 and insulinlike growth factor binding protein levels, functional status, and mortality in older adults. J Am Geriatr Soc, 56(4):652-60.
[97] Lazarus DD, Moldawer LL, Lowry SF (1993). Insulinlike growth factor-1 activity is inhibited by interleukin1 alpha, tumor necrosis factor-alpha, and interleukin-6. Lymphokine Cytokine Res, 12(4):219-23.

[98] Barbieri M, Ferrucci L, Ragno E, Corsi A, Bandinelli S, Bonafè M, et al (2003). Chronic inflammation and the effect of IGF-I on muscle strength and power in older persons. Am J Physiol Endocrinol Metab, 284(3):E4817.

[99] Zhong Y, Chen AF, Zhao J, Gu Y-J, Fu G-X (2016). Serum levels of cathepsin D, sirtuin1, and endothelial nitric oxide synthase are correlatively reduced in elderly healthy people. Aging Clin Exp Res, 28(4):641645.

[100] Kumar R, Chaterjee P, Sharma PK, Singh AK, Gupta A, Gill K, et al (2013). Sirtuin1: A Promising Serum Protein Marker for Early Detection of Alzheimer's Disease. PLoS One, 8(4):e61560.

[101] Kumar R1, Mohan N, Upadhyay AD, Singh AP, Sahu V, Dwivedi S, et al (2014). Identification of serum sirtuins as novel noninvasive protein markers for frailty. Aging Cell, 13(6):975-980.

[102] Baur JA, Ungvari Z, Minor RK, Le Couteur DG, de Cabo R (2012). Are sirtuins viable targets for improving healthspan and lifespan? Nat Rev Drug Discov, 11(6):443-461.

[103] Ma L, Dong W, Wang R, Li Y, Xu B, Zhang J, et al (2015). Effect of caloric restriction on the SIRT1/mTOR signaling pathways in senile mice. Brain Res Bull, 116:67-72.

[104] Le Couteur DG, Benson VL, McMahon AC, Blyth F, Handelsman DJ, Seibel MJ, et al (2011). Determinants of Serum-Induced SIRT1 Expression in Older Men: The CHAMP Study. Journals Gerontol Ser A Biol Sci Med Sci, 66A(1):3-8.

[105] Ma L1, Niu H, Sha G, Zhang Y, Liu P, Li Y (2019). Serum SIRT1 is Associated with Frailty and Adipokines in Older Adults. J Nutr Health Aging, 23(3):246-250.

[106] Razi S, Cogger VC, Kennerson M, Benson VL, McMahon AC, Blyth FM, et al (2017). SIRT1 Polymorphisms and Serum-Induced SIRT1 Protein Expression in Aging and Frailty: The CHAMP Study. Journals Gerontol Ser A, 72(7):870-876.

[107] Serra-Prat M, Palomera E, Clave P, Puig-Domingo M (2009). Effect of age and frailty on ghrelin and cholecystokinin responses to a meal test. Am J Clin Nutr, 89(5):1410-7.

[108] Kalyani RR, Varadhan R, Weiss CO, Fried LP, Cappola AR (2012). Frailty status and altered dynamics of circulating energy metabolism hormones after oral glucose in older women. J Nutr Health Aging, 16(8):679-86.

[109] Guillory B, Chen JA, Patel S, Luo J, Splenser A, Mody A, et al (2017). Deletion of ghrelin prevents agingassociated obesity and muscle dysfunction without affecting longevity. Aging Cell, 16(4):859-869.

[110] Gahete MD, Córdoba-Chacón J, Kineman RD, Luque RM, Castaño JP (2011). Role of ghrelin system in 
neuroprotection and cognitive functions: implications in Alzheimer's disease. Peptides, 32(11):2225-8.

[111] Huang R, Han J, Tian S, Cai R, Sun J, Shen Y, et al (2017). Association of plasma ghrelin levels and ghrelin rs4684677 polymorphism with mild cognitive impairment in type 2 diabetic patients. Oncotarget, 8(9):15126-15135.

[112] Theodoropoulou A, Metallinos IC, Psyrogiannis A, Vagenakis GA, Kyriazopoulou V (2012). Ghrelin and leptin secretion in patients with moderate Alzheimer's disease. J Nutr Health Aging, 16(5):472-7.

[113] Kunath N, Müller NCJ, Tonon M, Konrad BN, Pawlowski M, Kopczak A, et al (2016). Ghrelin modulates encoding-related brain function without enhancing memory formation in humans. Neuroimage, 142:465-473.

[114] Ruan Q, D'onofrio G, Wu T, Greco A, Sancarlo D, Yu Z1 (2017). Sexual dimorphism of frailty and cognitive impairment: Potential underlying mechanisms. Mol Med Rep, 16(3):3023-3033.

[115] Clegg A, Hassan-Smith Z (2018). Frailty and the endocrine system. Lancet Diabetes Endocrinol, 6(9):743-752.

[116] Abbatecola AM, Ferrucci L, Marfella R, Paolisso G (2007). Insulin Resistance and Cognitive Decline May Be Common Soil for Frailty Syndrome. Arch Intern Med, 167(19):2145-2146.

[117] Ma L, Wang J, Li Y (2015). Insulin resistance and cognitive dysfunction. Clin Chim Acta, 444:18-23.

[118] Barzilay JI, Blaum C, Moore T, Xue QL, Hirsch CH, Walston JD, et al (2007). Insulin resistance and inflammation as precursors of frailty: the Cardiovascular Health Study. Arch Intern Med, 167(7):635-41.

[119] Ma L, Feng M, Qian Y, Yang W, Liu J, Han R, et al (2015). Insulin Resistance Is an Important Risk Factor for Cognitive Impairment in Elderly Patients with Primary Hypertension. Yonsei Med J, 56(1):89-94.

[120] Pérez-Tasigchana RF, León-Muñoz LM, Lopez-Garcia E, Gutierrez-Fisac JL, Laclaustra M, RodríguezArtalejo F, et al (2017). Metabolic syndrome and insulin resistance are associated with frailty in older adults: a prospective cohort study. Age Ageing, 46(5):807-812.

[121] de la Monte SM, Wands JR (2008). Alzheimer's disease is type 3 diabetes-evidence reviewed. J Diabetes Sci Technol, 2(6):1101-13.

[122] Białas M1, Fiszer D, Rozwadowska N, Kosicki W, Jedrzejczak P, Kurpisz M (2009). The Role of IL-6, IL10, TNF- $\alpha$ and its Receptors TNFR 1 and TNFR2 in the Local Regulatory System of Normal and Impaired Human Spermatogenesis. Am J Reprod Immunol, 62(1):51-59.

[123] Ma L, Shao Z, Wang R, Zhao Z, Dong W, Zhang J, et al (2015). Rosiglitazone Improves Learning and Memory Ability in Rats with Type 2 Diabetes Through the Insulin Signaling Pathway. Am J Med Sci, 350(2):121-8.

[124] Dimova R, Tankova T, Kirilov G, Chakarova N, Dakovska L, Grozeva G (2016). Is vaspin related to cardio-metabolic status and autonomic function in early stages of glucose intolerance and in metabolic syndrome? Diabetol Metab Syndr, 8(1):46.

[125] Ma L, Sha G, Zhang Y, Li Y (2018). Elevated serum Il6 and adiponectin levels are associated with frailty and physical function in Chinese older adults. Clin Interv Aging, 13:2013-20.

[126] Huang C, Tomata Y, Kakizaki M, Sugawara Y, Hozawa A, Momma H, et al (2015). High circulating adiponectin levels predict decreased muscle strength among older adults aged 70 years and over: A prospective cohort study. Nutr Metab Cardiovasc Dis, 25(6):594-601.

[127] Tsai J-S, Wu CH, Chen SC, Huang KC, Chen CY, Chang CI, et al (2013). Plasma Adiponectin Levels Correlate Positively with an Increasing Number of Components of Frailty in Male Elders. PLoS One, 8(2): 56250.

[128] Persson J, Folkersen L, Ekstrand J, Helleberg J, Gabrielsen A, Lundman P, et al (2012). High plasma adiponectin concentration is associated with all-cause mortality in patients with carotid atherosclerosis. Atherosclerosis, 225(2):491-496.

[129] Li S, Shin HJ, Ding EL, van Dam RM (2009). Adiponectin Levels and Risk of Type 2 Diabetes. JAMA, 302(2):179.

[130] Wennberg AMV, Gustafson D, Hagen CE, Roberts RO, Knopman D, Jack C et al (2016). Serum Adiponectin Levels, Neuroimaging, and Cognition in the Mayo Clinic Study of Aging. J Alzheimer's Dis, 53(2):573581.

[131] De Franciscis P, Barbieri M, Leo S, Dalise AM, Sardu C, Marfella R, et al (2017). Serum adiponectin levels are associated with worse cognitive function in postmenopausal women. PLoS One, 12(12):e0186205.

[132] Lana A, Valdés-Bécares A, Buño A, RodríguezArtalejo F, Lopez-Garcia E (2017). Serum Leptin Concentration is Associated with Incident Frailty in Older Adults. Aging Dis, 8(2):240.

[133] Hamrick MW (2017). Role of the Cytokine-like Hormone Leptin in Muscle-bone Crosstalk with Aging. J Bone Metab, 24(1):1.

[134] Van Doorn C, Macht VA, Grillo CA, Reagan LP (2017). Leptin resistance and hippocampal behavioral deficits. Physiol Behav, 176:207-213.

[135] Maioli S, Lodeiro M, Merino-Serrais P, Falahati F, Khan W, Puerta E, et al (2015). Alterations in brain leptin signalling in spite of unchanged CSF leptin levels in Alzheimer's disease. Aging Cell, 14(1):122-9.

[136] Yin H, Tian S, Huang R, Cai R, Guo D, Lin H, et al (2018). Low Plasma Leptin and High Soluble Leptin Receptor Levels Are Associated With Mild Cognitive Impairment in Type 2 Diabetic Patients. Front Aging Neurosci, 10:132.

[137] Ulker M, Kenangil G (2017). The Relation of Circulating Levels of Leptin with Cognition in Patients with Alzheimer's Disease. Noro Psikiyatr Ars, 55(3):211-214.

[138] Mengel-From J, Thinggaard M, Dalgård C, Kyvik KO, Christensen K, Christiansen L (2014). Mitochondrial 
DNA copy number in peripheral blood cells declines with age and is associated with general health among elderly. Hum Genet, 133(9):1149-1159.

[139] Ashar FN, Moes A, Moore AZ, Grove ML, Chaves PHM, Coresh J, et al (2014). Association of mitochondrial DNA levels with frailty and all-cause mortality. J Mol Med, 93(2):177-186.

[140] Moore AZ, Biggs ML, Matteini A, O'Connor A, McGuire S, Beamer BA, et al (2010). Polymorphisms in the mitochondrial DNA control region and frailty in older adults. PLoS One, 5(6):12-16.

[141] Jensen GL (2008). Inflammation: roles in aging and sarcopenia. JPEN J Parenter Enteral Nutr, 32(6):656-9.

[142] Weinrich TW, Coyne A, Salt TE, Hogg C, Jeffery G (2017). Improving mitochondrial function significantly reduces metabolic, visual, motor and cognitive decline in aged Drosophila melanogaster. Neurobiol Aging, 60:34-43.

[143] Galluzzi L, Kepp O, Kroemer G (2012). Mitochondria: master regulators of danger signalling. Nat Rev Mol Cell Biol, 13(12):780-788.

[144] West AP, Shadel GS (2017). Mitochondrial DNA in innate immune responses and inflammatory pathology. Nat Rev Immunol, 17(6):363-375.

[145] Malik AN, Czajka A (2013). Is mitochondrial DNA content a potential biomarker of mitochondrial dysfunction? Mitochondrion, 13(5):481-492.

[146] Pinti M, Cevenini E, Nasi M, De Biasi S, Salvioli S, Monti D, et al (2014). Circulating mitochondrial DNA increases with age and is a familiar trait: Implications for "inflamm-aging." Eur J Immunol, 44(5):15521562.

[147] Pérez-Santiago J, De Oliveira MF, Var SR, Day TRC, Woods SP, Gianella S, et al (2017). Increased cell-free mitochondrial DNA is a marker of ongoing inflammation and better neurocognitive function in virologically suppressed HIV-infected individuals. J Neurovirol, 23(2):283-289.

[148] Lin MT, Beal MFF (2006). Mitochondrial dysfunction and oxidative stress in neurodegenerative diseases. Nature, 443(7113):787-795.

[149] Kregel KC, Zhang HJ (2007). An integrated view of oxidative stress in aging: basic mechanisms, functional effects, and pathological considerations. Am J Physiol Integr Comp Physiol, 292(1):R18-R36.

[150] Reid MB, Li YP (2001). Tumor necrosis factor-alpha and muscle wasting: a cellular perspective. Respir Res, 2(5):269-72.

[151] Carter CS, Hofer T, Seo AY, Leeuwenburgh C (2007). Molecular mechanisms of life- and health-span extension: role of calorie restriction and exercise intervention. Appl Physiol Nutr Metab, 32(5):954-66.

[152] Soysal P, Isik AT, Carvalho AF, Fernandes BS, Solmi M, Schofield P, et al (2017). Oxidative stress and frailty: A systematic review and synthesis of the best evidence. Maturitas, 99:66-72.

[153] McArdle A, Pollock N, Staunton CA, Jackson MJ (2019). Aberrant redox signalling and stress response in age-related muscle decline: Role in inter- and intracellular signalling. Free Radic Biol Med, 132:50-57.
[154] Viña J, Borras C, Gomez-Cabrera MC (2018). A free radical theory of frailty. Free Radic Biol Med, 124:358363.

[155] Revel F, Gilbert T, Roche S, Drai J, Blond E, Ecochard $\mathrm{R}$, et al (2015). Influence of Oxidative Stress Biomarkers on Cognitive Decline. J Alzheimer's Dis, 45(2):553-560.

[156] Velloso LA, Folli F, Saad MJ (2015). TLR4 at the Crossroads of Nutrients, Gut Microbiota, and Metabolic Inflammation. Endocr Rev, 36(3):245-71.

[157] Muenchhoff J, Song F, Poljak A, Crawford JD, Mather KA, Kochan NA, et al (2017). Plasma apolipoproteins and physical and cognitive health in very old individuals. Neurobiol Aging, 55:49-60.

[158] Eiriksdottir G, Aspelund T, Bjarnadottir K, Olafsdottir E, Gudnason V, Launer LJ, et al (2006). Apolipoprotein E genotype and statins affect CRP levels through independent and different mechanisms: AGESReykjavik Study. Atherosclerosis, 186(1):222-4.

[159] Schuitemaker A, Dik MG, Veerhuis R, Scheltens P, Schoonenboom NS, Hack CE, et al (2009). Inflammatory markers in $\mathrm{AD}$ and MCI patients with different biomarker profiles. Neurobiol Aging, 30(11):1885-9.

[160] Silverman JM, Beeri MS, Schmeidler J, Rosendorff C, Angelo G, Mavris RS, et al (2009). C-reactive protein and memory function suggest antagonistic pleiotropy in very old nondemented subjects. Age Ageing, 38(2):237-41.

[161] Silverman JM, Schmeidler J, Beeri MS, Rosendorff C, Sano M, Grossman HT, et al (2012). C-reactive protein and familial risk for dementia: a phenotype for successful cognitive aging. Neurology, 79(11):111623.

[162] Zhao S-J, Guo C-N, Wang M-Q, Chen W-J, Zhao Y-B (2012). Serum levels of inflammation factors and cognitive performance in amnestic mild cognitive impairment: A Chinese clinical study. Cytokine, 57(2):221-225.

[163] Montoliu T, Hidalgo V, Pulopulos MM, Ivorra JL, Martínez MJ, Salvador A (2018). The relationship between cortisol and cognitive function in healthy older people: The moderating role of Apolipoprotein $\mathrm{E}$ polymorphism. Neurobiol Learn Mem, 155:297-305.

[164] Sargent L, Nalls M, Starkweather A, Hobgood S, Thompson H, Amella EJ, et al (2018). Shared biological pathways for frailty and cognitive impairment: A systematic review. Ageing Res Rev, 47:149-158.

[165] Noble EE, Billington CJ, Kotz CM, Wang C (2011). The lighter side of BDNF. Am J Physiol Regul Integr Comp Physiol, 300(5):R1053-69.

[166] Inglés M, Gambini J, Mas-Bargues C, García-García FJ, Viña J, Borrás C (2016). Brain-Derived Neurotrophic Factor as a Marker of Cognitive Frailty. Journals Gerontol Ser A Biol Sci Med Sci, 72(3): 4501 .

[167] Coelho FM, ereira DS, Lustosa LP, Silva JP, Dias JM, Dias RC, et al (2012). Physical therapy intervention (PTI) increases plasma brain-derived neurotrophic 
factor (BDNF) levels in non-frail and pre-frail elderly women. Arch Gerontol Geriatr, 54(3):415-20.

[168] Modarresi F, Faghihi MA, Lopez-Toledano MA, Fatemi RP, Magistri M, Brothers SP, et al (2012). Inhibition of natural antisense transcripts in vivo results in gene-specific transcriptional upregulation. Nat Biotechnol, 30(5):453-9.

[169] Mekli K, Nazroo JY, Marshall AD, Kumari M, Pendleton N (2016). Proinflammatory genotype is associated with the frailty phenotype in the English Longitudinal Study of Ageing. Aging Clin Exp Res, 28(3):413-421.

[170] Almeida OP, Norman PE, van Bockxmeer FM, Hankey GJ, Flicker L (2012). CRP 1846G>A polymorphism increases risk of frailty. Maturitas, 71(3):261-6.

[171] Franceschi C, Bonafè M (2003). Centenarians as a model for healthy aging. Biochem Soc Trans, 31(2):457-61.

[172] Dong X, Zhang L, Meng Q, Gao Q (2017). Association Between Interleukin-1A, Interleukin-1B, and Bridging integrator 1 Polymorphisms and Alzheimer's Disease: a standard and Cumulative Meta-analysis. Mol Neurobiol, 54(1):736-747.

[173] Walston J, Arking DE, Fallin D, Li T, Beamer B, Xue $\mathrm{Q}$, et al (2005). IL-6 gene variation is not associated with increased serum levels of IL-6, muscle, weakness, or frailty in older women. Exp Gerontol, 40(4):344352.

[174] Puts MT, Visser M, Twisk JW, Deeg DJ, Lips P (2005). Endocrine and inflammatory markers as predictors of frailty. Clin Endocrinol (Oxf), 63(4):403-411.
[175] Ramos Dos Santos L, Belcavello L, Camporez D, Iamonde Maciel de Magalhães C, Zandonade E, Lírio Morelato R, et al (2016). Association study of the BIN1 and IL-6 genes on Alzheimer's disease. Neurosci Lett, 614:65-9.

[176] Mapstone M, Cheema AK, Fiandaca MS, Zhong X, Mhyre TR, MacArthur LH, et al (2014). Plasma phospholipids identify antecedent memory impairment in older adults. Nat Med, 20(4):415-418.

[177] Whiley L, Sen A, Heaton J, Proitsi P, García-Gómez D, Leung R, et al (2014). Evidence of altered phosphatidylcholine metabolism in Alzheimer's disease. Neurobiol Aging, 35(2):271-278.

[178] Schmitz G, Ruebsaamen K (2010). Metabolism and atherogenic disease association of lysophosphatidylcholine. Atherosclerosis, 208(1):1018.

[179] Wallace M, Morris C, O'Grada CM, Ryan M, Dillon ET, Coleman E, et al (1586). Relationship between the lipidome, inflammatory markers and insulin resistance. Mol BioSyst, 10:1586-1595.

[180] Gonzalez-Freire M, Moaddel R, Sun K, Fabbri E, Zhang P, Khadeer M, et al (2019). Targeted Metabolomics Shows Low Plasma Lysophosphatidylcholine 18:2 Predicts Greater Decline of Gait Speed in Older Adults: The Baltimore Longitudinal Study of Aging. Journals Gerontol Ser A, 74(1):62-67.

[181] Panza F, Lozupone M, Solfrizzi V, Stallone R, Bellomo A, Greco A, et al (2017). Cognitive frailty: a potential target for secondary prevention of dementia. Expert Opin Drug Metab Toxicol, 13(10):1023-1027. 